DOI: http://dx.doi.org/10.19177/reen.v9e12016118-151

http://portaldeperiodicos.unisul.br/index.php/EeN/index

\title{
COCRIAÇÃO DE VALOR: UMA BIBLIOMETRIA DE 2000 A 2014
}

\section{VALUE CO-CREATION: A BIBLIOMETRIC FROM 2000 TO 2014}

\section{CO-CREACIÓN DE VALOR: UNA BIBLIOMETRÍA DESDE 2000 HASTA 2014}

\author{
Henrique César Melo Ribeiro \\ Doutor em Administração de Empresas pela Universidade Nove de Julho (UNINOVE) \\ Professor Adjunto da Universidade Federal do Piauí, Campus Ministro Reis Velloso \\ Endereço: Av. São Sebastião, n. 2819, CEP: 64202020. Parnaíba, PI, Brasil \\ Telefone: (86) 3323-5248 \\ E-mail: hcmribeiro@gmail.com
}

\section{Vanessa Carvalho Miranda Tavares}

Mestrado Profissional em Administração e Gestão de Esporte pela Universidade Nove de Julho (UNINOVE)

Endereço: Av. Francisco Matarazzo,n. 612, Bloco C, 1ำ andar, CEP: 05001100. São Paulo, SP, Brasil Telefone: (11) 3665-9344

E-mail: vancmt@yahoo.com.br

\section{Benny Kramer Costa}

Pós-doutorado em Administração pela Universidade de São Paulo (USP)

Professor do Programa de Pós-graduação em Administração da Universidade Nove de Julho (UNINOVE)

Endereço: Av. Francisco Matarazzo,n. 612, Bloco C, 1ำ andar, CEP: 05001100. São Paulo, SP, Brasil Telefone: (11) 3665-9344

E-mail: benny.costa@yahoo.com

Artigo recebido em 31/01/2016. Revisado por pares em 21/02/2016. Reformulado em 21/02/2016. Recomendado para publicação em 28/03/2016, por Ademar Dutra (Editor Científico). Publicado em 30/04/2015. Avaliado pelo Sistema double blind review. 


\section{RESUMO}

O objetivo deste estudo foi investigar as características da produção científica do tema Cocriação de Valor nas bases de dados Web of Science e Scopus no período de 2000 a 2014. Utilizou-se a técnica de análise bibliométrica. Verificou-se a evolução do tema Cocriação de Valor. Vargo e Lusch foram os pesquisadores mais citados e mais profícuos. Este estudo contribuiu para difundir, socializar e nortear a temática cocriação de valor na literatura acadêmica nacional, colaborando para melhor entendimento de suas nuances, que influenciam em sua importância como tema emergente no contexto acadêmico e no campo do conhecimento Administração.

Palavras-chave: Cocriação de valor; Produção científica; Periódicos internacionais; Bibliometria.

\section{ABSTRACT}

The objective of this study was to investigate the characteristics of scientific production on the theme Co-creation Value in Web of Science and Scopus databases from 2000 to 2014. We used the bibliometric analysis technique. There was an evolution of the subject Cocreation Value. Vargo and Lusch were the most frequent and most profitable researchers. This study helped to spread, socialize and guide the thematic Co-creation Value in the national academic literature, contributing to understanding nuances that influence its importance as an emerging theme in the academic context and knowledge on the field Management.

Keywords: Co-creation of value; Scientific production; International journals; Bibliometrics.

\section{RESUMEN}

El objetivo de este estudio fue investigar las características de la producción científica del tema Co-creación de Valor en las bases de datos Web of Science y Scopus en el periodo de 2000 hasta 2014. Fue utilizada la técnica de análisis bibliométrico. Fue verificada una evolución del tema Co-creación de Valor. Vargo y Lusch fueron los investigadores más citados y más proficuos. Este estudio contribuye para difundir, socializar y nortear la temática co-creación de valor en la literatura académica nacional, colaborando para mejor comprensión de sus matices, que influencian en su importancia como tema emergente en el contexto académico y en el campo del conocimiento Administración.

Palabras-clave: Co-creación de valor; Producción científica; Periódicos internacionales; Bibliometría. 


\section{INTRODUÇÃO}

O tema cocriação de valor tem sido estudado na Administração ao longo dos últimos 15 anos, e no decorrer desse tempo, tem sido considerada a participação ativa dos clientes/consumidores (PRAHALAD; RAMASWAMY, 2004; VARGO; LUSCH, 2004; HOYER et al., 2010) no processo de criação de valor.

Com o desenvolvimento organizacional na maneira de pensar e realizar, ocorreu o afastamento em relação à forma tradicional de criação de valor, sugerindo que as empresas criem valor e repassem aos seus clientes/consumidores, realizando um esforço conjunto. Por meio do processo do relacionamento entre empresa e cliente/consumidor, cocriam-se experiências personalizadas (PRAHALAD; RAMASWAMY, 2004). Esta concepção tem ganhado espaço diante do olhar tradicional de criação de valor das organizações (PRAHALAD; RAMASWAMY, 2004). A postura tradicional enfatiza que o valor era centralizado e oferecido pela organização, com seu olhar voltado para dentro da empresa, em busca de eficiência e redução de seus custos, com a intenção de obter maior lucro (PRAHALAD; RAMASWAMY, 2004; VARGO; LUSCH, 2004).

As organizações vêm sendo desafiadas e impulsionadas a buscar novas estratégias de negócios (LUSCH; VARGO, 2006), e devido ao dinamismo neste cenário, há a necessidade que se adequem às mudanças tecnológicas, facilitando a obtenção de informações (YUNIS et al., 2012). Em contrapartida, dispõem de suas informações para o mercado, por isso tem sido requerido de diversas áreas de atuação uma atenção efetiva voltada para as necessidades dos clientes.

Sendo assim, coloca-se a seguinte questão de pesquisa que norteou este trabalho: Qual é o perfil da produção científica do tema cocriação de valor publicado no ISI Web of Science e na base de dados Scopus no período de 2000 a 2014? O objetivo destaca-se: investigar as características da produção científica do tema cocriação de valor nas bases de dados Web of Science e Scopus no período de 2000 a 2014.

Revista Eletrônica de Estratégia \& Negócios, Florianópolis, v.9, n.1, jan./abr. 2016. 
Diante do exposto, esta pesquisa justifica-se pela relevância do tema cocriação de valor para os gestores de diversas áreas, e como uma oportunidade de enfatizar uma estratégia para o desenvolvimento de negócios. Ressalta-se que, ao final deste estudo, pretende-se contribuir para o aperfeiçoamento e atualização dos estudiosos sobre o tema de cocriação de valor, além de disseminar o conhecimento e contribuir para a literatura acadêmica internacional, e especialmente a nacional, cooperando para a difusão do saber científico no âmbito da área da Administração e afins.

A escolha das bases de dados Web of Science e Scopus ocorreu pela percepção que diversas pesquisas as utilizaram para a realização de estudos bibliométricos como fontes preciosas de informações. Os estudos de Bar-llan (2008) e Falagas et al. (2008) utilizaram ambas as bases de dados em suas respectivas pesquisas. Pinheiro et al. (2015) mapearam informações sobre a indústria criativa na base Scopus. Já na base de dados ISI web of Science foram feitos mapeamentos na área da saúde por Zauber et al. (2012), e na gestão do esporte, especificamente sobre a governança corporativa nos esportes, por Ribeiro, Costa e Ferreira (2015). Entre outros estudos realizados em ambas as bases ou utilizando-as individualmente, ressaltam-se suas relevâncias no sentido de comparações de conteúdos literários disponíveis. Diante disso, reforça-se que este estudo pretende investigar a produção científica do tema cocriação de valor nas duas bases de dados no período de 2000 a 2014.

Essa escolha permitiu uma visão ampla de publicações científicas sobre o tema cocriação de valor por meio dos periódicos indexados nas bases ISI Web of Science e Scopus, a fim de visualizar seu desenvolvimento e seu impacto no âmbito internacional. Ressaltam Guz e Rushchitsky (2009) que Web of Science e Scopus são consideradas as maiores bases de dados por abrangerem diversos campos de estudos científicos, e são frequentemente utilizados para pesquisa de literaturas. Em relação ao ISI Web of Science, Vieira e Gomes (2009) afirmam que há anos é a base de dados que aborda todos os domínios da ciência. Embora a Scopus tenha sida introduzida em 2004, é uma boa alternativa para pesquisa, sendo considerada por Rew (2010), expandida e atualizada para a busca de citações e resumos.

Revista Eletrônica de Estratégia \& Negócios, Florianópolis, v.9, n.1, jan./abr. 2016. 
O conceito de cocriação de valor apareceu em 2000, com o sentido geral de participação do cliente na produção, atribuída a Prahalad e Ramaswamy (2000) a autoria do termo cocreation em um artigo da Harvard Business Review, e posteriormente o tema foi retomado e mais desenvolvido por Prahalad e Ramaswamy (2004) no livro O Futuro da competição, ampliando a ideia que foi atrelada ao âmbito dos negócios e, por esta razão, este estudo justifica-se e inicia com a pesquisa a partir do ano 2000.

Este estudo irá trabalhar a bibliometria como estratégia de pesquisa, (FERREIRA et al., 2011; RIBEIRO et al., 2012), sendo relevante para a análise e avaliação da ciência produzida em diferentes áreas do conhecimento em âmbito regional, nacional e internacional, no intuito de mapear o tema da cocriação de valor desde sua primeira menção.

Estudos em diversas áreas de atuação já se utilizaram da bibliometria, tais como: na Tecnologia (DAIM et al., 2006), na Sustentabilidade (HID; NASCIMENTO; OLIVEIRA, 2012), em Engenharia Genética (SZU-CHIA, 2010), em Educação Superior (HONG YEOH; KAUR, 2008), na Ciência da Informação (CAl; CARD, 2008), na Contabilidade (SOUZA et al., 2012), e recentemente foi encontrado um estudo internacional sobre cocriação de valor com a intenção de sumarizar e classificar as pesquisas sobre o tema no decorrer de sua existência, além de identificar suas perspectivas teóricas e as conexões entre elas (GALVAGNO; DALLI, 2014).

Este artigo está organizado em cinco partes. A primeira contempla a introdução, com a justificativa, questão e o objetivo da pesquisa. O referencial teórico é exposto na segunda parte. Após, são descritos os procedimentos metodológicos usados para a pesquisa. A quarta parte aborda a análise e discussão dos resultados. Conclui-se com as considerações finais, limitações da pesquisa e as recomendações para estudos futuros.

\section{FUNDAMENTAÇÃO TEÓRICA}

Esta seção explana sobre a bibliometria, seguida dos conceitos e o desenvolvimento da temática de cocriação de valor.

\subsection{BIBLIOMETRIA}

Revista Eletrônica de Estratégia \& Negócios, Florianópolis, v.9, n.1, jan./abr. 2016. 
A bibliometria é o estudo dos aspectos quantitativos da produção, disseminação e uso da informação registrada com emprego de métodos matemáticos e estatísticos (SPINAK, 1996). É uma técnica de pesquisa que permite a mensuração da produção científica (NEDERHOF, 2006) a fim de contribuir e disseminar os conteúdos no ambiente acadêmico (HID; NASCIMENTO; OLIVEIRA, 2012), possibilitando contar, através das análises de publicações, citações e também co-citações (CRONIN, 2001), permitindo a visualização que pode ocorrer em diferentes níveis acadêmicos, vislumbrando a qualidade das publicações (GLÄNZEL et al., 2006). Pode ser considerado um passeio no patamar internacional de publicações (SMITH; HAZELTON, 2008), permitindo saber o país, território, idioma e área de publicação (TSAI, 2013).

Os estudos de bibliometria permitem a construção e disseminação do conhecimento científico (SUBRAMANYAM, 1983; RIBEIRO; COSTA; FERREIRA, 2015; SERRA; FERREIRA; ALMEIDA; VANZ, 2012), como mencionado anteriormente. Porém, Daim et al. (2006), ressaltam que esse tipo de estudo permite a compreensão do passado e a predição para estudos futuros, inclusive de temas recentes, incrementa Ribeiro (2013), além de permitir um número considerável para auxiliar estudiosos em diversos temas. A disseminação do conhecimento e o desenvolvimento da temática que se quer fomentar dependem da exposição e circulação delas, por meio de publicações, em livros e principalmente em revistas científicas (HOFFMAN; HOLBROOK, 1993).

Segundo Pádua (2004), a finalidade das pesquisas bibliométricas é colocar o pesquisador em contato com o que já foi produzido anteriormente a respeito do tema de pesquisa de interesse. Para Cruz e Ribeiro (2003, p. 12), um estudo bibliométrico "pode visar um elemento dos trabalhos realizados anteriormente sobre o mesmo tema estudado no momento, pode identificar e selecionar os métodos e técnicas a serem utilizados, além de fornecer subsídios" para a pesquisa, como é o caso do recente estudo encontrado sobre o tema aqui abordado, realizado internacionalmente por Galvagno e Dalli (2014). Outra vantagem de utilizar a bibliometria, afirmam Hayashi et al. (2007), é perceber o número e frequência das publicações cronologicamente, possibilitando a avaliação de grupos de pesquisadores e universidades.

Revista Eletrônica de Estratégia \& Negócios, Florianópolis, v.9, n.1, jan./abr. 2016. 
Para Michels e Schmoch (2014), houve um aumento significativo da utilização da técnica de pesquisa da bibliometria com o propósito de avaliação de temas de interesse em diversas áreas do conhecimento, e o motivo foi porque as análises prévias eram subjetivas. A influência à realização de análises bibliométricas na ciência, para Michels e Schmoch (2014), veio de países como a Austrália, Noruega, Reino Unido, ou Espanha, e guiou a mudança de comportamento dos autores cientistas de forma positiva (WEINGART, 2005; BORNMANN, 2010), contribuindo para a produção científica e sua disseminação.

El-Maamiry e Abid Ghauri (2013) complementam que a bibliometria é altamente utilizada por bibliotecas e pela ciência da informação. Contudo, impacta significativamente em outras áreas de estudo, pois diversos campos de pesquisa utilizam da bibliometria para expor a relevância de sua área de atuação.

Isto posto, torna-se relevante o estudo sobre a cocriação de valor, uma vez que o tema vem ganhando espaço, mas ainda é pouco difundido. Internacionalmente, os estudos na temática de cocriação de valor vêm ganhando destaque e adquirindo cada vez maior espaço no meio acadêmico, com a replicação de estudos já consagrados em diversos setores, tais como: gestão de negócios (PRAHALAD; RAMASWAMY, 2004; VARGO; LUSCH, 2004), na saúde (MCCOLL-KENNEDY et al. 2012), no marketing (RANJAN; READ, 2014), em projetos de construção civil (AAPAOJA; HAAPASALO; SÖDERSTRÖM, 2013), em departamentos de polícia (DEGNEGAARD; DEGNEGAARD; COUGHLAN, 2015), e mais recentemente no campo do esporte (HEDLUND, 2014; UHRICH, 2014), afirmando que é possível a ocorrência da cocriação de valor, tornando sua prática relevante para a contribuição com a estratégia de negócios em diversificadas áreas de atuação.

\subsection{COCRIAÇÃO DE VALOR: INTRODUÇÃO E EVOLUÇÃO}

O tema cocriação de valor tem sido estudado na Administração ao longo dos últimos 15 anos. No decorrer desse tempo, tem-se considerado a participação ativa dos clientes/consumidores (PRAHALAD; RAMASWAMY, 2000; PRAHALAD; RAMASWAMY, 2004; VARGO; LUSCH, 2004) no processo de criação de valor nas organizações.

Observa-se que quatro elementos, chamados de blocos de interação, são considerados como primordiais para deixar a maneira tradicional das organizações que Revista Eletrônica de Estratégia \& Negócios, Florianópolis, v.9, n.1, jan./abr. 2016. 
retinham as informações sobre o produto e serviço, baseados no princípio de que os clientes não deveriam compartilhar suas decisões naquilo que thes era oferecido. Prahalad e Ramaswamy (2004) concluíram que isto é possível somente para as empresas que desafiem os papeis tradicionais das organizações, aderindo os blocos de interação entre ambos, e suas combinações para criar capacitações novas e importantes, e criaram o modelo seminal de cocriação de valor chamado DART (Diálogo, Acesso, Risco e Transparência).

O processo da cocriação de valor, conforme o modelo proposto por Prahalad e Ramaswamy (2004), está baseado na interação dos clientes com a organização provedora de produtos e serviços, contando que, durante qualquer fase da criação até o produto ou serviço acabado, a organização adote a postura de colocar em prática os desejos dos clientes, que são o foco final pelo qual o produto e serviço estão sendo idealizados. Para Becker e De Brito Nagel (2013), o processo de interação é necessário para o sucesso do produto ou serviço. A seguir mostra-se uma explanação do modelo DART que está proposto com os blocos de interação que sustentam a cocriação de valor.

O Diálogo gera interatividade, e uma oportunidade de estimular a troca de conhecimento entre a organização e o cliente, a fim de sanar questões de interesse mútuo para suprir necessidades e expectativas. O Acesso, enquanto o foco das organizações tradicionais era de criar e transferir seus produtos e serviços, a busca do cliente como agente ativo por informações sobre o bem e o produto é cada vez maior, é um meio de o cliente experimentar o produto sem a obrigatoriedade de possuí-lo. A Transparência contribui para uma relação mais produtiva e de maior valor agregado, apontando para o desaparecimento da assimetria de informações entre organizações e clientes. O RiscoBenefício: parte do princípio das organizações tradicionais de que saberiam avaliar e administrar os riscos de que os clientes que, por seu papel ativo, tornam-se também responsáveis pelo processo de cocriação de valor.

Enquanto os autores Prahalad e Ramaswamy (2004) adotam o modelo que aponta para o que as organizações podem fazer para serem partes do processo de cocriação de valor, Payne, Storbacka e Frow (2008), em seus estudos, propõem um modelo que informasse como esse processo poderia ser colocado em prática, e ressaltam a importância do relacionamento entre a organização e o cliente como grupo de experiências e atividades Revista Eletrônica de Estratégia \& Negócios, Florianópolis, v.9, n.1, jan./abr. 2016. 
longitudinais, dinâmicas interativas, não lineares e, muitas vezes, inconscientes. Essa experiência, segundo Payne, Storbacka e Frow (2008), é influenciada por fatores emocionais (características da personalidade, humor e sentimentos), cognitivos (desenvolvidos por meio de informações presentes na memória) e comportamentais (ações que derivam e resultam de experiências). Com bases nesses fundamentos, Payne, Storbacka e Frow (2008) definiram o modelo que chamaram de processo de encontros.

O processo de encontros para a cocriação de valor inicia com a compreensão, por parte da organização, de reconhecer o cliente como cocriador de valor. Isto se torna explícito quando a organização dispõe de oportunidades de experiências que sejam relevantes para o cliente, facilitando o aprendizado da organização. Contudo, deve identificar a oportunidade de cocriação, planejar e testar para ser assertivo nas propostas de valor agregado (PAYNE; STORBACKA; FROW, 2008).

Detalham Payne, Storbacka e Frow (2008) que esse processo envolve os pontos de contato, e com cuidado são definidos por parte da organização quais serão os canais utilizados para promover esse encontro, sejam eles comportamentais (ulitização do produto e testes), cognitivo (uso de roteiros, testemunhais ou promessas de funcionalidade), ou baseados na emoções (uso de metáforas ou surpresas), variando conforme o tipo de negócio.

A comparação dos modelos de blocos de interação de Prahalad e Ramaswamy (2004), e de Payne, Storbacka e Frow (2008), com o modelo do processo de encontro dos clientes e seus os pontos de contato mostram detalhadamente como o cliente interage e cria a experiência de cocriação de valor por meio de processos pessoais e pontos de encontros propícios para que ocorra de fato a cocriação de valor.

Prahalad e Ramaswamy (2004) comentam que os consumidores tornam-se cada vez mais ativos, não mais se conformando com o que lhes era imposto pelas organizações, e no cenário atual, torna-se mais participativo na escolha de um produto ou serviço. A interatividade com o consumidor é essencial (VARGO; LUSCH, 2004), o envolvimento e a inclusão do consumidor nos processos de desenvolvimento, que não acaba na linha de 
produção, mas as contribuições dos clientes podem ser aplicadas aos produtos que serão comercializados, possibilitando alcances maiores em satisfação.

Para Grönroos (2000), o valor não é proporcionado pela organização, mas o processo de geração de valor é efetivo com o envolvimento do cliente, e o mesmo autor, complementando os seus estudos em 2011, afirma que as organizações se encontram em um processo de busca ao equilíbrio entre a oferta dos produtos, disponibilizando aos clientes a integração de diversos recursos com práticas e processo (GRÖNROOS; RAVALD, 2011).

Outra vertente relevante da cocriação de valor é a combinação de inovação e troca de recursos, e também da habilidade para acessar, implantar, trocar e combinar os referidos recursos: este é o principal ponto da criação de valor. A troca entre empresa e o consumidor facilita o processo de cocriação de valor, fazendo com que se torne mais ativo e aliado (NAMBISAM; NAMBISAM, 2008). O interesse por parte do cliente é despertado quando a organização dispõe, no mercado, um produto ou serviço que apresenta diferencial superior aos demais disponíveis (PAYNE; STORBACKA; FROW, 2008), sendo percebido pela utilização.

Ramaswamy (2008) descreve o exemplo da Nike, ressaltando que é possível que grandes líderes se adequem à realidade de ter clientes mais bem informados e interessados no produto e serviço provido, conectados em redes e dispostos a diálogos abertos. No passado, adquirir um tênis, um agasalho, era o final da experiência dos clientes da Nike. Porém, este cenário veio se modificando e, agora, é a aquisição de um produto ou serviço o início de um processo interativo que produz relacionamento, que gera a cocriação de valor: por meio das opiniões é possível uma customização dos produtos oferecidos no mercado, proporcionando o aprendizado com os clientes que consomem seus produtos, permitindo com que a organização se coloque de forma impositiva no mercado e ganhe papel de destaque em relação às concorrentes (RAMASWAMY, 2008).

Na dinâmica da cocriação de valor, as organizações desafiam o papel tradicional de hierarquização, ressaltando que o envolvimento dos interessados que, para Ramaswamy e Gouillart (2010), desenvolve a ideia de ajustar expectativas dos clientes e da organização, propondo o framework dos quatro poderes da cocriação de valor. Os quatro poderes da Revista Eletrônica de Estratégia \& Negócios, Florianópolis, v.9, n.1, jan./abr. 2016. 
cocriação são: Por parte da organização - Maior capital estratégico e retornos, e Menores riscos e custos. Por parte do cliente - Novas experiências, e Menores riscos e custos (RAMASWAMY; GOUILLART, 2010).

Com intuito de alinhar as ideias e expectativas dos clientes e das organizações, Hoyer et al. (2010), afirmam que o valor aumenta todas as vezes que o cliente está envolvido no processo da cocriação de valor, tornando-se uma abordagem muito atraente para as organizações, por refletir as necessidades e expectativas dos seus clientes, que ganham uma proporção significativa quando se trata do desenvolvimento de um novo produto (NPD -

New Product Development. Mencionam Hoyer et al. (2010) que o envolvimento do consumidor no desenvolvimento de um novo produto melhora a qualidade, reduz o risco e aumenta a aceitação do mercado.

A cocriação de valor vem sendo apresentada como a mais recente e inovadora oportunidade de estratégia de negócios e casos de inclusão positiva de clientes, para que sejam vistos como sucesso em diversos setores organizacionais, e também apontam para benefícios gerados reciprocamente nesse processo (PRAHALAD; RAMASWAMY, 2004; LUSCH; VARGO, 2006; ZHANG; CHEN, 2008; MORAES; COSTA, 2013). Este processo ainda não é claro e bem definido no ambiente dos negócios e da ciência (BECKER; DE BRITO NAGEL, 2013), porém, argumentos conceituais vêm sendo desenvolvidos na tentativa de identificar a cocriação de valor, e grande parte deles são realizados a partir de estudos de casos que apontam, nas organizações, aspectos da cocriação de valor em diferentes setores e os benefícios atrelados a estas práticas.

\section{PROCEDIMENTOS METOdOLÓGICOS}

Este estudo caracteriza-se como descritivo, com abordagem qualitativa, porém, com predominância na quantitativa, por se tratar de um levantamento bibliométrico (NASCIMENTO; BEUREN, 2011), ou seja, utilizou-se as técnicas de análise bibliométrica (NASCIMENTO; JUNQUEIRA; MARTINS, 2010; BALESTRIN; VERSCHOORE; REYES JUNIOR, 2010) que se destinam a quantificar e analisar a produção científica de temas (COOPER; LINDSAY, 1998), e sua importância ocorre como norte e estratégia para futuros trabalhos. 
É importante ressaltar que a bibliometria, como disciplina científica, desenvolveu um grupo de leis que referenciam os estudos de forma sistêmica (MORETTI; CAMPANÁRIO, 2009), sendo oriundas, respectivamente, de três pesquisadores que se destacam por suas importantes descobertas, Bradford, Lotka e Zipf (VANTI, 2002), sendo as mais conhecidas e utilizadas quando atreladas à produção e comunicação científica (BUFREM; PRATES, 2005). A bibliometria desenvolveu-se mediante a elaboração de leis empíricas sobre o comportamento da literatura (EGGHE, 2005); neste contexto, é importante conhecer as três leis básicas da bibliometria para que haja melhor entendimento dos dados.

A Lei de Bradford mensura o nível de relevância dos periódicos sobre determinada área (ACEDO; CASILLAS, 2005). Já a Lei de Lotka descreve a produtividade e as citações de autores por meio de um modelo de distribuição de tamanho-frequência, em um conjunto de pesquisas, evidenciando aspectos de coautoria. E a Lei de Zipf calcula a quantidade de ocorrências das palavras em vários textos, gerando uma lista de terminações de determinado assunto, sendo utilizada para observar qual tema científico é tratado nos trabalhos (EGGHE, 2005).

Portanto, esta pesquisa trata-se de um estudo longitudinal com dados de um período de 15 anos, de 2000 a 2014. Os artigos foram procurados com base nas seguintes palavras-chave: Cocreation, Co-creation, Value Co-creation e Value Cocreation. Cada uma das palavras-chave foi usada na captura dos papers, de maneira não simultânea, nos seguintes locais dos estudos: título, palavras chave, e resumo. Ou seja, cada palavra-chave foi usada para buscar os estudos que versavam sobre o tema cocriação de valor no título, nas palavras-chave e resumo dos artigos, de maneira individual e não simultânea, para que fossem encontrados todos os artigos que se caracterizassem sobre o tema ora investigado. É importante destacar que, para encontro dos termos Cocreation, Co-creation, Value Cocreation e Value Cocreation foram buscados e selecionados trabalhos nas áreas de Administração, Contabilidade, Economia, Finanças, Turismo e Esporte.

\subsection{AMOSTRA}

Revista Eletrônica de Estratégia \& Negócios, Florianópolis, v.9, n.1, jan./abr. 2016. 
Para investigar o perfil das pesquisas e o crescimento de publicações no tema da cocriação de valor, foi realizada a coleta de dados em artigos publicados no período de 2000 a 2014, o que ressalta o levantamento longitudinal de 15 anos.

Os dados foram coletados nas bases de dados ISI Web of Science e Scopus. Como visto anteriormente, o critério utilizado para a busca e seleção dos artigos nos periódicos internacionais envolveu as seguintes palavras-chave: Cocreation, Co-creation, Value Cocreation e Value Cocreation, com intuito de identificar artigos que incluíssem esses termos, na tentativa de mapear o maior número de publicações sobre a temática no decorrer de sua existência no campo internacional. A amostra final permitiu que fossem encontrados 98 artigos em ambas as bibliotecas digitais que publicaram trabalhos com o tema cocriação de valor.

A amostra final foi composta por de 75 artigos com o termo na base ISI Web of Science e 22 trabalhos com na base Scoppus, totalizando 97 textos encontrados entre os anos de 2000 a 2014. Ressalta-se que, durante a pesquisa, foi possível verificar as revistas científicas que se encontraram mais proeminentes por meio do fator de impacto, que aparecem no Quadro 1. Em outras palavras, estes periódicos destacaram-se pelos seus respectivos fatores de impacto, e todos estes periódicos acadêmicos compuseram a amostra final deste estudo.

Quadro 1 - Revistas científicas que se destacaram pelos seus respectivos fatores de impacto

\begin{tabular}{|c|c|c|}
\hline \multicolumn{3}{|c|}{ Fator de Impacto das Revistas } \\
\hline Posição & Revista & Fator de Impacto \\
\hline 1은 & MIS Quarterly & 5,310 \\
\hline 20 & Proceedings of the IEEE & 4,930 \\
\hline 3으 & Journal of marketing & 3,930 \\
\hline 40 & Journal of supply chain management & 3,850 \\
\hline 50 & Journal of the academy of marketing science & 3,810 \\
\hline 60 & Organization science & 3,770 \\
\hline 70 & Journal of medical internacional research & 3,420 \\
\hline 80 & Journal of marketing research & 3,100 \\
\hline 9은 & Annals of tourism research & 2,600 \\
\hline 10 & Journal of the academy of marital and family therapy & 2,560 \\
\hline 110 & Journal of Advertising research & 2,560 \\
\hline $12 \div$ & Journal of business research & 2,480 \\
\hline 130 & Journal of service research & 2,480 \\
\hline 140 & Information System reaseach & 2,430 \\
\hline
\end{tabular}

Revista Eletrônica de Estratégia \& Negócios, Florianópolis, v.9, n.1, jan./abr. 2016. 


\begin{tabular}{|c|l|r|}
\hline 150 & Journal of service research & 2,400 \\
\hline 160 & Systems, Man and Cybernetics, Part A: Systems and Humans & 2,180 \\
\hline 170 & International journal of production economics & 2,080 \\
\hline 180 & Journal of management information systems & 2,060 \\
\hline 190 & Journal of service management & 2,000 \\
\hline 20 o & Internacional journal of hospitality management & 1,930 \\
\hline
\end{tabular}

Fonte: Bases de dados ISI Web of Science e Scoppus (2015).

O instrumento utilizado para coleta e análise de dados foi um roteiro estruturado em banco de dados em planilha MS Excel, balizando, para o mapeamento dos artigos os seguintes indicadores: (I) evolução dos artigos, (II) artigos com maior número de citações, (III) artigos que mostraram simultaneamente os termos value cocreation e cocreation, (IV) autoria, (V) autores, (VI) Instituições de Ensino Superior (IESs), (VII) países e (VIII) temas. Para a análise de dados foi feita uma análise descritiva por veículo de publicação, bem como vínculo institucional, localidade, ano de publicação e artigos por autor.

Segundo Bardin (2009), existem várias formas de agrupar artigos por categorias, as quais reúnem um grupo de elementos sobre um título genérico, sendo a razão de suas características comuns. Neste estudo, a opção foi mapear e agrupar artigos internacionais para evidenciar a cocriação de valor nas áreas das Ciências Sociais, Administração, Administração Pública, Estratégia, Engenharia, Economia, Contabilidade, Marketing, Turismo, Ciência da Computação e Comunicação.

\section{ANÁLISE DE DADOS E DISCUSSÃO DOS RESULTADOS}

A análise dos indicadores foi feita de maneira quantitativa e descritiva, contendo a análise bibliométrica de 97 artigos de âmbito internacional, que está dividida em 8 tópicos: (I) evolução dos artigos, (II) artigos com maior número de citações, (III) artigos que mostraram simultaneamente os termos value cocreation e cocreation, (IV) autoria, (V) autores, (VI) Instituições de Ensino Superior (IESs), (VII) países e (VIII) temas.

\subsection{PUBLICAÇÕES AO LONGO DOS ANOS}

A Figura 1 apresenta o número de artigos publicados sobre o tema cocriação de valor no estudo longitudinal de 2000 a 2014.

Figura 1 - Evolução do número de artigos publicados sobre cocriação de valor por ano

Revista Eletrônica de Estratégia \& Negócios, Florianópolis, v.9, n.1, jan./abr. 2016. 


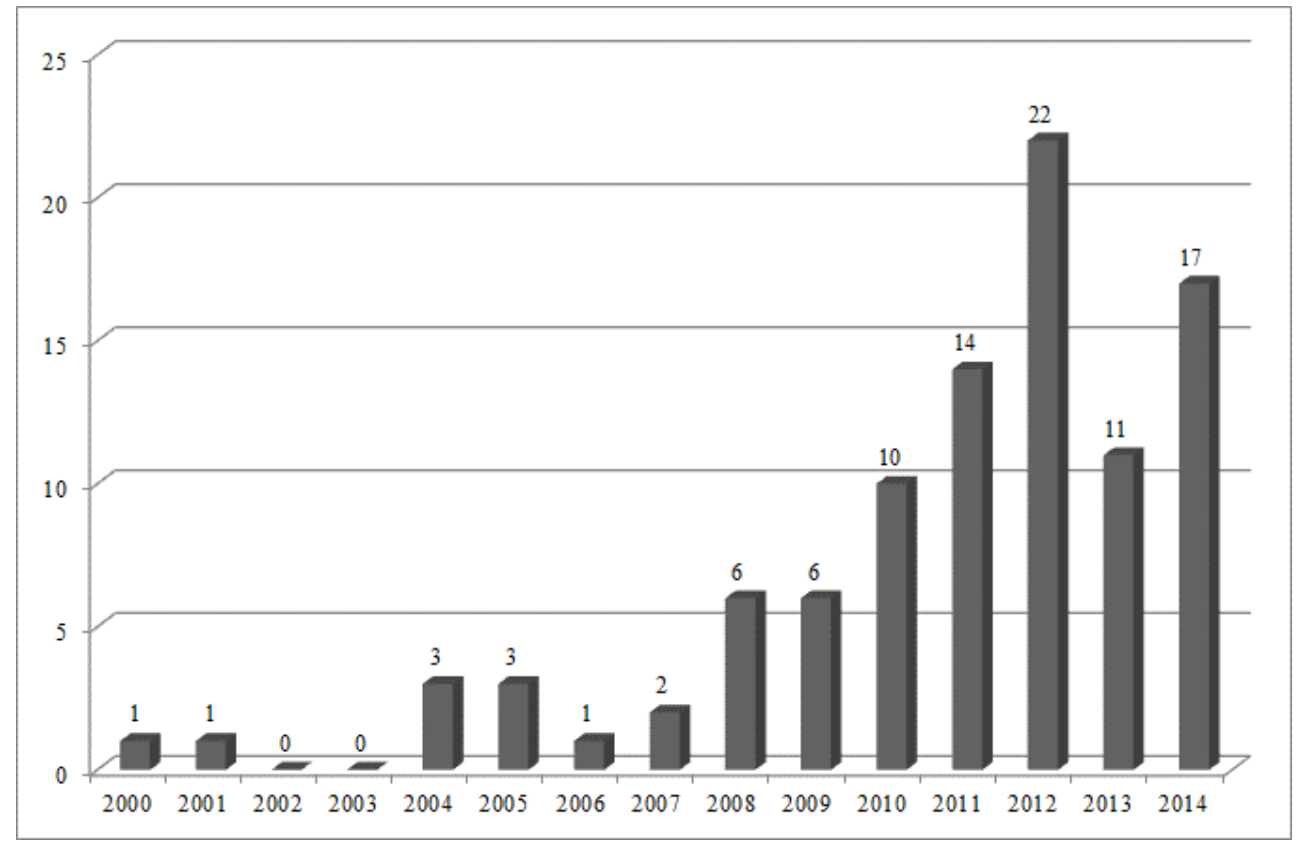

Fonte: Dados da pesquisa (2015).

Ao Analisar os dados da pesquisa percebe-se que, com o decorrer dos anos, a temática cocriação de valor foi evoluindo e ganhando mais espaço, demonstrando ascendência a partir do ano 2008. Tal evolução é confirmada através dos estudos de Prahalad e Ramaswamy (2000), Prahalad e Ramaswamy (2004), Vargo e Lusch (2004) que, por meio de suas respectivas pesquisas e resultados, demonstram o crescimento do tema cocriação de valor no meio acadêmico e, consequentemente, de sua importância e relevância como estratégia empresarial no âmbito organizacional global.

Payne, Storbacka e Frow (2008) corroboram com tal achado, ao evidenciar que os estudos sobre cocriação de valor estavam ainda em sua fase inicial no âmbito acadêmico. Desde então notou-se um aumento gradativo nas publicações em 2008, mais fortemente se destacando na área do Marketing. Em 2012, as publicações atingiram seu ápice de interesse maior de outras áreas de atuação como, por exemplo, Administração e Estratégia, aumentando, com isso, a justificativa para tal crescimento das publicações sobre o tema em investigação.

Os achados contemplados aqui contribuem para evidenciar o crescimento do tema ora investigado, proporcionando, assim, um norte de melhor entendimento e compreensão do estado da arte deste tema para a literatura acadêmica nacional, e invariavelmente trará a possibilidade de difusão e publicação de novos estudos por parte de acadêmicos seniores e 
ou juniores, acarretando sua maior propagação no contexto científico internacional, impactando de maneira acessiva no âmbito acadêmico nacional.

\subsection{ARTIGOS COM MAIOR NÚMERO DE CITAÇÕES}

A análise das citações pode ser vista como fator principal para assiduidade das pesquisas, pois apreciará qual(is) autor(es) é (são) mais citado(s) em determinado tema, contribuindo um norte para pesquisadores experientes e principalmente para os iniciantes, entusiasmando de maneira direta o crescimento de futuras pesquisas sobre a temática e contribuindo a posteriori na socialização e otimização do assunto analisado (RIBEIRO et al., 2012) que é a cocriação de valor.

A seguir, o Quadro 2 evidencia os artigos mais citados durante o período que este estudo se propôs a analisar, e o Quadro 3 apresenta os artigos que constam os dois termos escolhidos para seleção: value cocreation e cocreation.

Quadro 2 - Artigos com maior número de citações de 2000 a 2014

\begin{tabular}{|c|c|}
\hline $\begin{array}{l}\text { № } \\
\text { Citações }\end{array}$ & Artigos mais citados \\
\hline 1907 & Vargo, S. L., \& Lusch, R. F. (2004). Evolving to a new dominant logic for marketing. \\
\hline 230 & $\begin{array}{l}\text { Ostrom, A. L., Bitner, M. J., Brown, S. W., Burkhard, K. A., Goul, M., Smith-Daniels, V.; Rabinovich, } \\
\text { E. (2010). Moving forward and making a difference: research priorities for the science of service. }\end{array}$ \\
\hline 103 & $\begin{array}{l}\text { Van Doorn, J., Lemon, K. N., Mittal, V., Nass, S., Pick, D., Pirner, P., \& Verhoef, P. C. (2010). } \\
\text { Customer engagement behavior: Theoretical foundations and research directions. }\end{array}$ \\
\hline 91 & $\begin{array}{l}\text { Hoyer, W. D., Chandy, R., Dorotic, M., Krafft, M., \& Singh, S. S. (2010). Consumer cocreation in new } \\
\text { product development. }\end{array}$ \\
\hline & $\begin{array}{l}\text { Sheth, J. N., Sisodia, R. S., \& Sharma, A. (2000). The antecedents and consequences of customer- } \\
\text { centric marketing. }\end{array}$ \\
\hline 77 & $\begin{array}{l}\text { Nambisan, S., \& Baron, R. A. (2009). Virtual customer environments: testing a model of voluntary } \\
\text { participation in value co-creation activities. }\end{array}$ \\
\hline 68 & Brodie, R. J., Hollebeek, L. D., Juric, B., \& Ilic, A. (2011). Customer engagement: conceptual domain, \\
\hline
\end{tabular}

Revista Eletrônica de Estratégia \& Negócios, Florianópolis, v.9, n.1, jan./abr. 2016. 


\begin{tabular}{|l|l|}
\hline & \begin{tabular}{l} 
fundamental propositions, and implications for research. \\
\hline 66
\end{tabular} \\
\hline 63 & $\begin{array}{l}\text { Vargo, S. L. (2008). Customer integration and value creation Paradigmatic Traps and Perspectives. } \\
\text { loyalty. }\end{array}$ \\
\hline 57 & $\begin{array}{l}\text { Payne, A., Storbacka, K., Frow, P., \& Knox, S. (2009). Co-creating brands: Diagnosing and designing } \\
\text { the relationship experience. }\end{array}$ \\
\hline 54 & $\begin{array}{l}\text { Edvardsson, B., Enquist, B., \& Johnston, R. (2005). Cocreating customer value through hyperreality } \\
\text { in the prepurchase service experience. }\end{array}$ \\
\hline
\end{tabular}

Fonte: Dados da pesquisa (2015).

Verificando o Quadro 2, o qual evidencia os artigos mais citados no que tange ao tema cocriação de valor de 2000 a 2014, tem-se que todos estes são desde 2000 até 2011. Isso reforça os achados de que o citado tema ainda é embrionário na literatura científica internacional, vislumbrando, assim, um panorama de que estudos sobre o citado tema e suas temáticas que o compõem ainda é, no referido período, um campo emergente de estudos, impactando no surgimento de novos estudiosos sobre o assunto. Isto possibilita o aparecimento de acadêmicos que se destacam sobre o assunto, acarretando respectivamente em suas importâncias no aspecto teórico e comportamental do tema cocriação de valor criando, com isso, invariavelmente, uma condição de usar e ou utilizar tais pesquisadores legitimados da área como embasamento teórico. Assim, acarreta em suas concomitantes importâncias na difusão e socialização do conhecimento da cocriação de valor, fomentando, com isso, seus respectivos estudos e fazer valer a essencialidade de suas citações, como é demonstrado no Quadro 2 deste estudo.

Destes autores, destacam-se Vargo e Lusch como os mais citados, e também são enfatizados como os acadêmicos com maior produção acadêmica sobre o tema cocriação (Figura 3) de valor nas revistas internacionais. A afirmativa e o achado remetem ao que foi evidenciado no parágrafo anterior, demonstrando que, mesmo o tema sendo incipiente ainda na literatura científica internacional, o mesmo está em fase de crescimento (Figura 1), sobretudo por causa de estudiosos do tema que a partir de 2000, que deram a largada para

Revista Eletrônica de Estratégia \& Negócios, Florianópolis, v.9, n.1, jan./abr. 2016. 
a publicação, difusão e disseminação do assunto em investigação no âmbito acadêmico global.

\subsection{ARTIGOS QUE MOSTRARAM SIMULTANEAMENTE OS TERMOS UTILIZADOS PARA BUSCA}

O Quadro 3 complementa com informações o Quadro 2, ressaltando os artigos encontrados com os termos simultâneos utilizados para a busca e seleção dos trabalhos (Cocreation, Co-creation, Value Co-creation e Value Cocreation) encontrados no título, resumo ou palavras-chave.

Quadro 3 - Artigos que apresentaram simultaneamente os termos: cocreation, co-creation, value co-creation e value cocreation

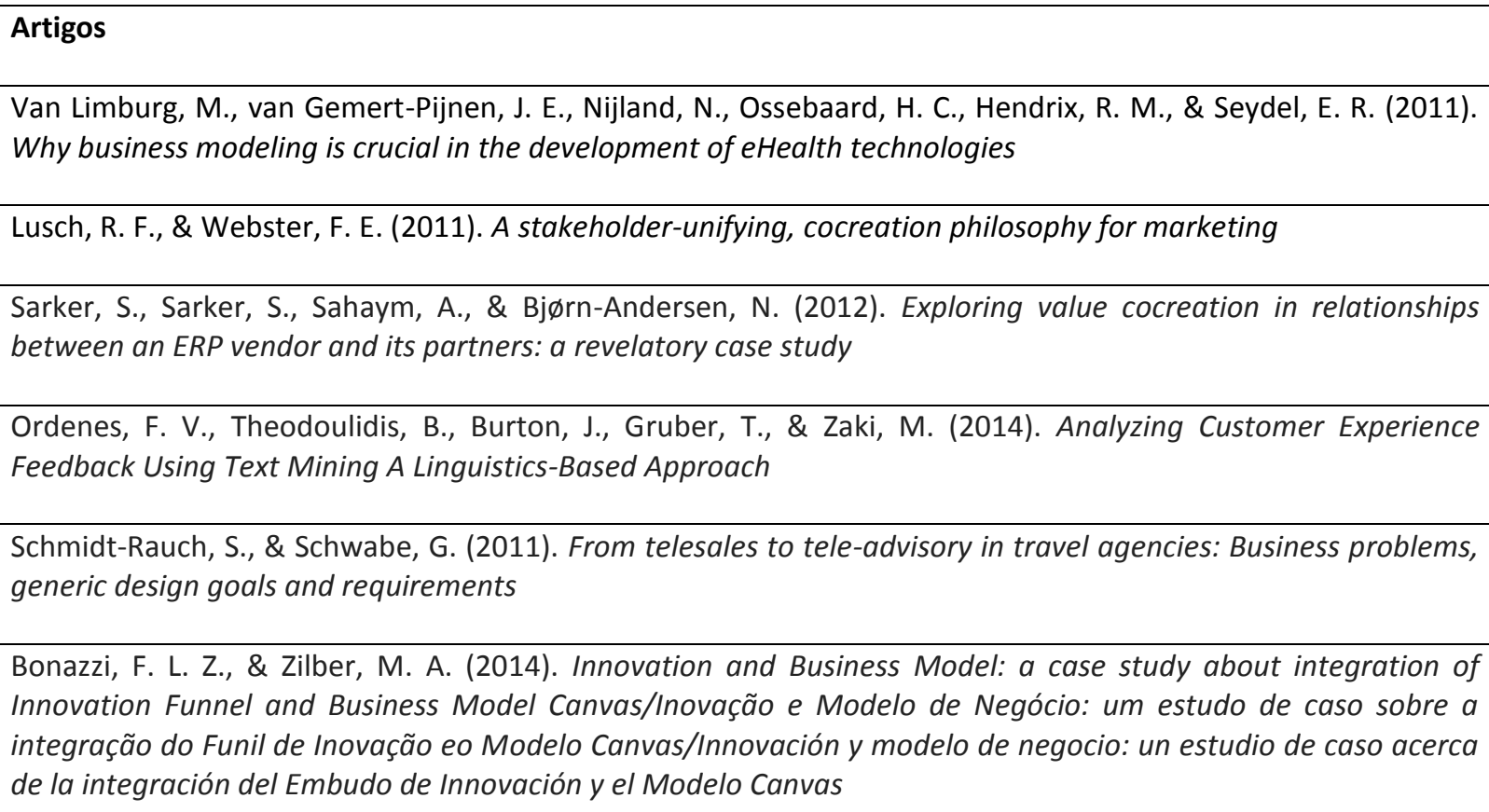

Schmidt-Rauch, S., \& Schwabe, G. (2011). From telesales to tele-advisory in travel agencies: Business problems, generic design goals and requirements

Bonazzi, F. L. Z., \& Zilber, M. A. (2014). Innovation and Business Model: a case study about integration of Innovation Funnel and Business Model Canvas/Inovação e Modelo de Negócio: um estudo de caso sobre a integração do Funil de Inovação eo Modelo Canvas/Innovación y modelo de negocio: un estudio de caso acerca de la integración del Embudo de Innovación y el Modelo Canvas

Fonte: Dados da pesquisa.

Analisando o Quadro 3, verifica-se que os artigos que abordaram os termos cocreation, co-creation, value co-creation e value cocreation simultaneamente são relativamente recentes, sendo os mais antigos datados de 2011. O que mostra que o tema cocriação de valor, mesmo sendo emergente nas publicações visualizadas na Figura 1, ainda é incipiente no contexto acadêmico internacional, visto que existem poucos estudos que versam em conjunto as palavras-chave usadas para a busca não simultânea de artigos sobre cocriação de valor neste estudo.

Revista Eletrônica de Estratégia \& Negócios, Florianópolis, v.9, n.1, jan./abr. 2016. 
Os achados desta seção ajudam a elucidar que, apesar da busca não simultânea destas palavras-chave sobre cocriação de valor de 2000 a 2014, foram encontrados somente 97 estudos, o que mostra que é necessário e é uma grande oportunidade para os acadêmicos e para os estudiosos sobre cocriação de valor de fomentar, difundir e disseminar mais estudos sobre o citado tema, impactando de maneira direta em sua ascensão no contexto literário acadêmico internacional, e influenciando, também, de forma direta, no âmbito literário acadêmico nacional.

\subsection{ARTIGOS COM MAIOR NÚMERO DE COAUTORIAS}

Para verificação e contagem de autores e autoria, foram seguidas as sugestões de Alvarado (2002), que recomenda a contagem completa dos autores: seja ele principal ou secundário, é creditado com uma contribuição, sendo demonstrando essa informação na Figura 2.

Figura 2 - Autoria dos artigos pesquisados

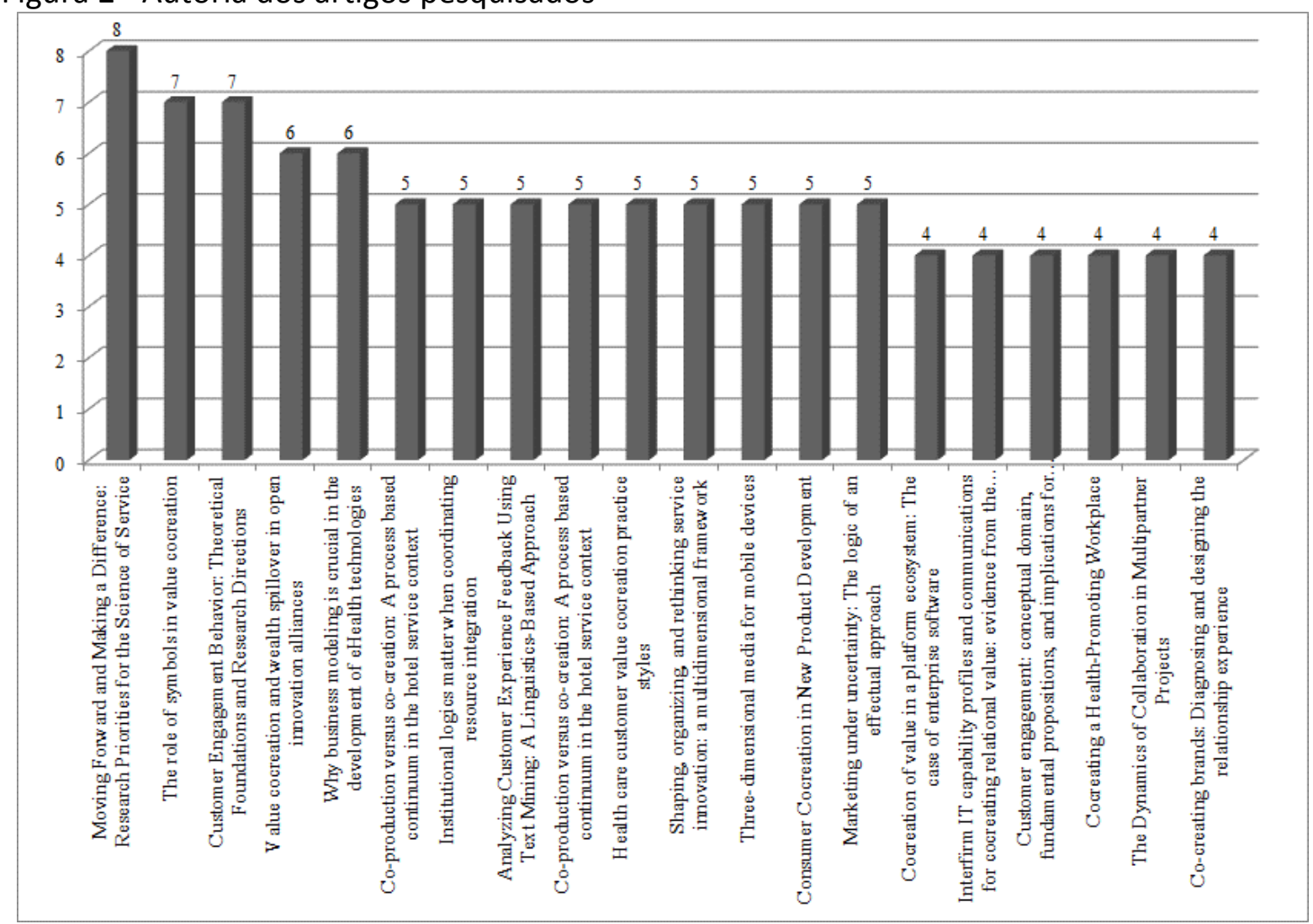

Fonte: Dados da pesquisa (2015).

Analisando a Figura 2, observou-se que o artigo que se encontrou com o maior número de coautores foi desenvolvido por um autor e sete coautores, totalizando 8 Revista Eletrônica de Estratégia \& Negócios, Florianópolis, v.9, n.1, jan./abr. 2016. 
pesquisadores trabalhando em parceria no estudo. Em seguida surgiram dois estudos com sete acadêmicos em parceria para a produção destes respectivos estudos.

Tal achado nesta seção contribui para aferir que o número de autores que publicam cada artigo comprova redes e parcerias entre pesquisadores, configurando, assim, um importante gerador de produção científica, sobretudo para o tema em investigação. Na medida em que mais acadêmicos publicam em conjunto, percebe-se que o tema é investigado por grupos de pesquisa, ao invés de pesquisadores individuais (RIBEIRO et al., 2012). Neste contexto, ressalva-se que a colaboração entre autores vem sendo vista internacionalmente como um dos indicadores de qualidade dos estudos, especificamente em temas emergentes (SUBRAMANYAM, 1983), como é o caso da temática cocriação de valor.

\subsection{AUTORES MAIS PROFÍCUOS}

A análise dos pesquisadores que mais publicam em determinado tema manifesta, primeiramente, a emergencia do assunto. Temas emergentes tendem a ter autores com histórico de pesquisa acentuada (NEDERHOF, 2006). Diante disso, ressalva-se que a Figura 3 permite visualizar os autores mais profícuos sobre a produção acadêmica do tema cocriação de valor.

Figura 3 - Autores mais profícuos

Revista Eletrônica de Estratégia \& Negócios, Florianópolis, v.9, n.1, jan./abr. 2016. 


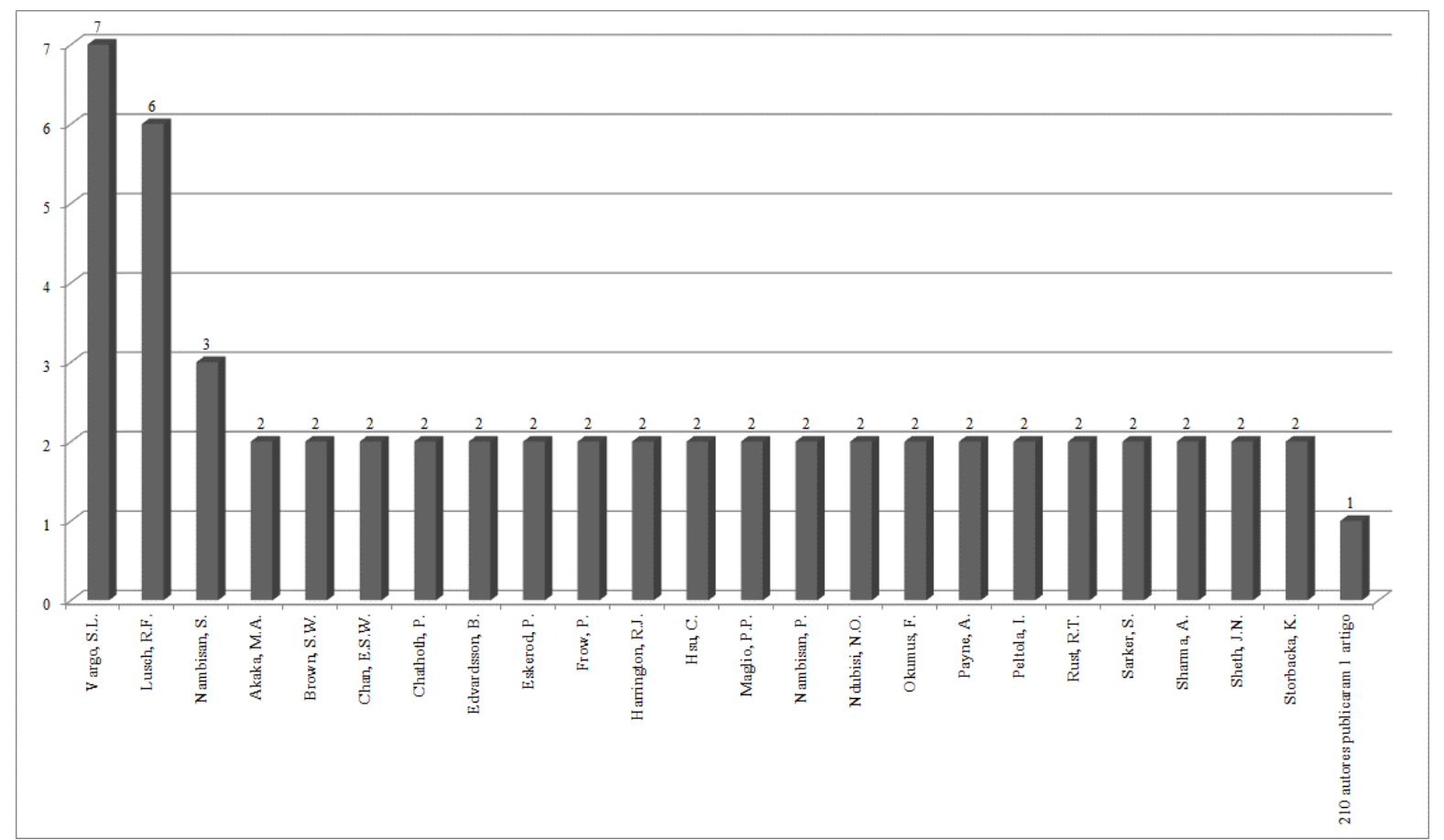

Fonte: Dados da pesquisa (2015).

Os autores Vargo e Lusch foram os mais profícuos neste estudo, com sete e seis artigos publicados, respectivamente, sobre o tema cocriação de valor, de 2000 a 2014 . Tal afirmação confirma e corrobora com os achados do Quadro 2, o qual mostra que os citados autores, além de serem os mais produtivos sobre o tema em evidência, também são os mais citados.

Realça-se, também, o pesquisador Nambisan, com três artigos publicados e com dois aparecem os acadêmicos: Akaka, Brown, Chan, Chathoth, Edvardsson, Eskerod, Frow, Harrington, Hsu, Maglio, Nambisan, Ndubisi, Okumus, Payne, Peltola, Rust, Sarker, Sharma, Sheth e Storbacka. Com apenas uma publicação tem-se 210 autores. Tal resultado remete à importância destes autores para o fomento, difusão, disseminação e consolidação do tema cocriação de valor no âmbito internacional.

No instante em que estes autores contribuem nessa consolidação, auxiliamm para o surgimento de novas pesquisas, com novos acadêmicos interessados sobre o tema, colaborando, assim, de maneira direta para a geração de novos projetos de pesquisa. Isto impacta no interesse direto ou indireto de novos alunos para a iniciação científica sobre o tema e, consequentemente, na otimização e surgimento de novos grupos de trabalho. 
Então, viabiliza a evolução do tema cocriação de valor, não somente no contexto macro da literatura acadêmica internacional (RIBEIRO et al., 2012), também no panorama nacional.

\subsection{INSTITUIÇÕES DE ENSINO SUPERIOR COM MAIOR NÚMERO DE PUBLICAÇÕES}

A origem do conhecimento pode ser analisada não apenas quanto à autoria, mas também por meio das respectivas IES dos autores que, de acordo com o método de pesquisa, é um dos indicadores trabalhados, sendo essencial para responder à questão de pesquisa deste estudo (RIBEIRO; COSTA; FERREIRA, 2015). Diante do exposto, a Figura 4 aborda as IES com maior número de publicações sobre o tema cocriação de valor de 2000 a 2014.

Figura 4 - IESs com maior número de publicações

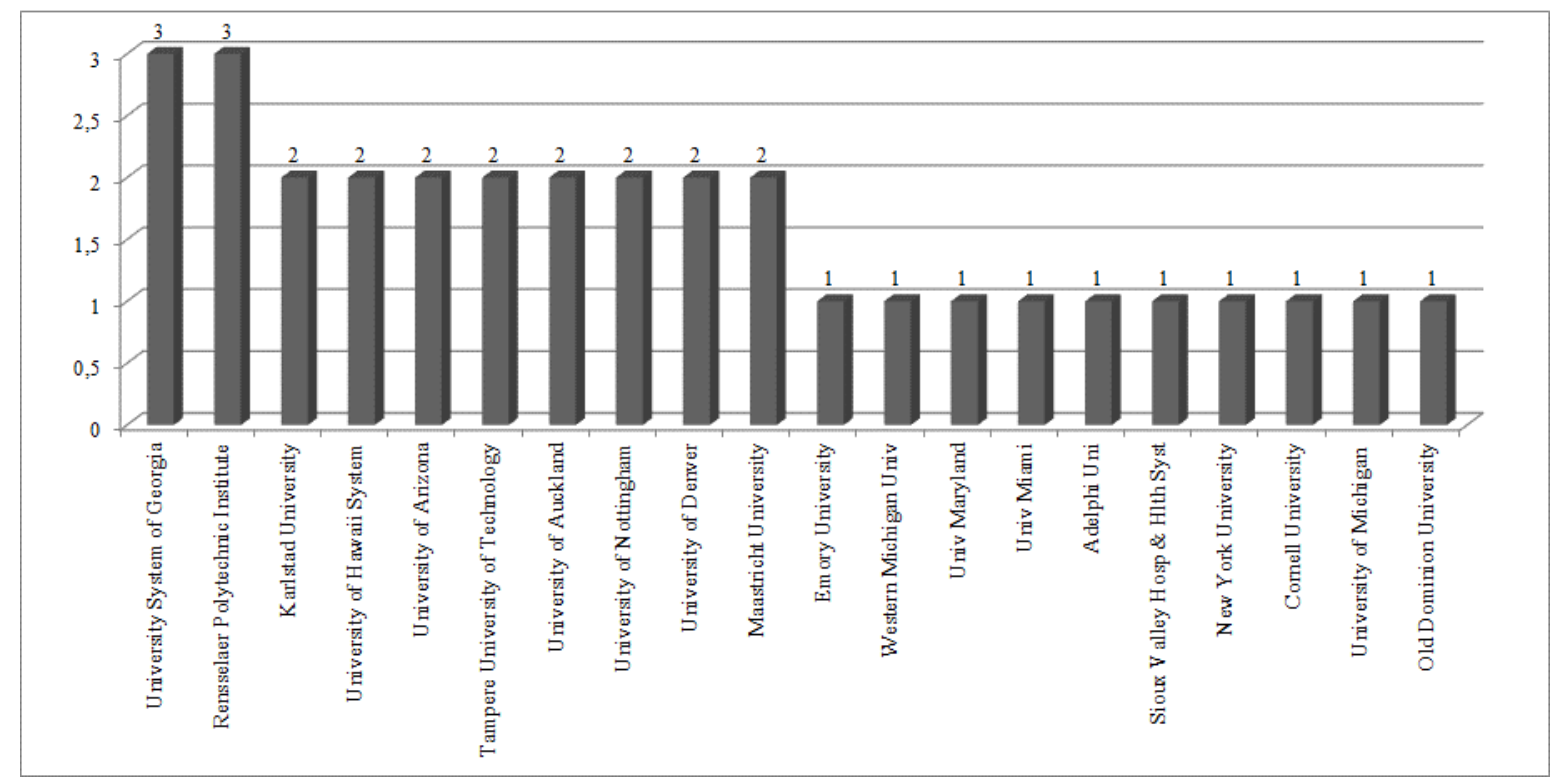

Fonte: Dados da pesquisa (2015).

Devido ao tema cocriação de valor ainda ser incipiente no contexto literário internacional, impacta diretamente na dimensão das IES, visto que as instituições que se destacam na produção e publicação de artigos sobre o assunto em investigação só tem três estudos divulgados, são elas: University System of Georgia e Rensselaer Polytechnic Institute.

Com duas publicações aparecem as IES: Karlstad University, University of Hawaii System, University of Arizona, Tampere University of Technology, University of Auckland, University of Nottingham, University of Denver e Maastricht University. Com uma publicação surgem as IES: Emory University, Western Michigan University, University Maryland, Revista Eletrônica de Estratégia \& Negócios, Florianópolis, v.9, n.1, jan./abr. 2016. 
University Miami, Adelphi University, Sioux Valley Hosp \& HIth Syst, New York University, Cornell University, University of Michigan e Old Dominion University.

Os achados desta seção contribuem para compreender o panorama embrionário que o assunto em questão se encontra no âmbito científico internacional, visto que ainda são poucas as IES que publicaram e/ou estão em destaque (por meio dos vínculos de seus respectivos autores) no cenário acadêmico internacional.

Outra contribuição pertinente neste estudo é que estas universidades que se destacaram, e de alguma forma as que tiveram divulgações de artigos sobre o tema cocriação de valor, são as mais importantes sobre o tema, influenciando, por meio de seus autores, que se vinculam às mesmas, na propagação e socialização do tema. Com isso ocorre o fomento e crescimento do assunto ora estudado, corroborando com os dados e informações anteriormente vistas, no que se refere a evidenciar que o citado tema ainda é incipiente; contudo, mostra-se em evolução no cenário científico internacional.

\subsection{PAÍSES COM MAIOR NÚMERO DE PUBLICAÇÕES}

Complementando as informações da Figura 4, que demonstra as IES com maior produção acadêmica do tema em investigação, segue a Figura 5, que mostra os países que publicaram sobre o tema cocriação de valor, ficando enfatizada a importância dos Estados Unidos da América (EUA) na difusão e disseminação do conhecimento científico sobre o referido tema.

Figura 5 - Países que obtiveram maior número de publicações 


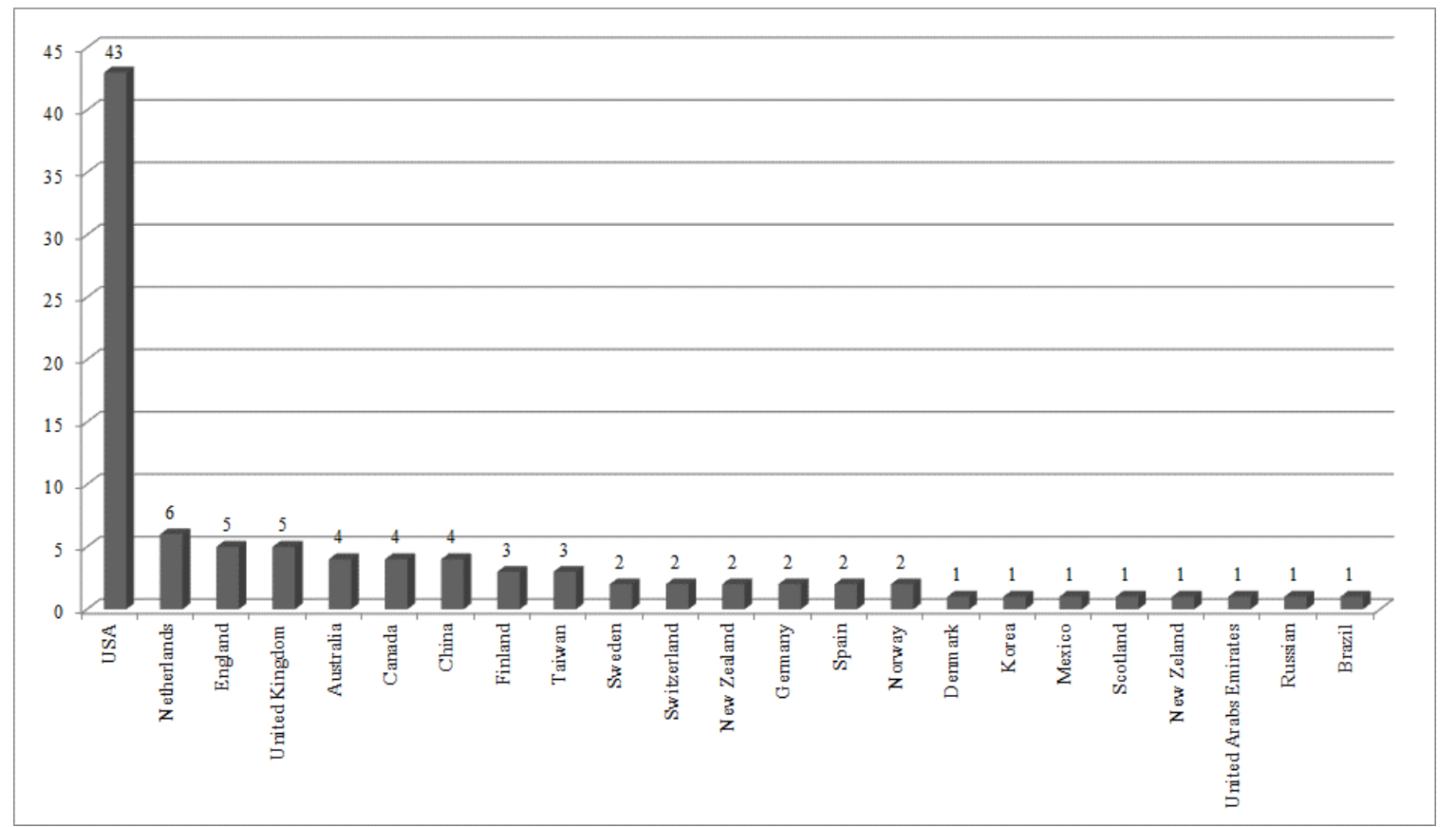

Fonte: Dados da pesquisa (2015).

Observando a Figura 5, a mesma permite vislumbrar que os EUA publicaram aproximadamente $44 \%$ dos trabalhos sobre o tema em análise neste estudo. Tal discrepância e domínio dos EUA, no que tange a publicação da temática cocriação de valor, deve-se ao fato de que há também um domínio das IES americanas nesta pesquisa, impactando diretamente na supremacia americana na divulgação de estudos sobre cocriação de valor. Outros estudos similares a este, porém, enfatizando temas, como estratégia e governança corporativa (RIBEIRO, 2014; RIBEIRO; COSTA; FERREIRA, 2014), corroboram com os achados desta seção, pois, também colocam os EUA em destaque na produção científica destes outros assuntos no âmbito acadêmico mundial.

Outros 22 países aparecem na Figura 5, e destes, o Brasil surge com apenas uma publicação sobre o tema em investigação. Neste contexto, realça-se que o tema cocriação de valor, apesar de ser embrionário no contexto internacional, o mesmo encontra-se em evolução, como é salientado e visualizado na Figura 1 deste estudo. Entretanto, no Brasil, o tema cocriação de valor, pelos dados aferidos nesta pesquisa, encontra-se muito incipiente.

Diante do exposto, este estudo surge como contribuição forte no contexto acadêmico nacional, pois coloca em evidencia um tema ainda pouco pesquisado no cenário nacional, proporcionando, assim, uma possibilidade de que outros acadêmicos e/ou estudiosos sobre o assunto em questão venham a propagar, fomentar e disseminar outros Revista Eletrônica de Estratégia \& Negócios, Florianópolis, v.9, n.1, jan./abr. 2016. 
estudos similares a este. Para isso, é possível que se ou adotem outras técnicas de análise e/ou outros métodos científicos, contribuindo para que o tema cocriação de valor seja mais divulgado e socializado no Brasil, em congressos, seminários e em revistas de baixo fator de impacto, e até em periódicos de forte fator de impacto, ajudando, assim, este citado tema a versar um estado de emergência daqui alguns anos.

\subsection{TEMAS}

A Tabela 1 aborda os temas pesquisados neste estudo durante o período selecionado, ou seja, de 2000 a 2014. O tema e/ou campo do conhecimento que se destacou nas publicações sobre o assunto cocriação de valor foi Negócios e Economia, com 35 artigos publicados. Estes assuntos em destaque são realçados e colocados como imprescindíveis para estudos sobre cocriação de valor, visto que o citado tema é preponderante para os negócios, impactando na economia global (PRAHALAD; RAMASWAMY, 2004; VARGO; LUSCH, 2004; LUSCH; VARGO, 2006).

Outras temáticas e/ou áreas do saber surgem como assuntos que se ligam diretamente com o tema principal deste estudo, ou seja, a cocriação de valor, são eles: Ciência da Computação, Marketing, Engenharia, Contabilidade, Comportamento Organizacional, Gestão de Recursos Humanos, Turismo, Psicologia, Ciência Social, Artes e Humanidades, Comunicação, Inovação, Direito, Cultura, Gestão de Operações, Saúde, Administração Pública e Gestão Ambiental.

Os achados descritos no parágrafo anterior são corroborados por meio dos respectivos estudos e achados dos autores Prahalad e Ramaswamy (2004), Vargo e Lusch (2004), Mccoll-Kennedy et al. (2012), Ranjan e Read (2014), Aapaoja, Haapasalo e Söderström (2013), Degnegaard, Degnegaard e Coughlan (2015), Hedlund (2014) e Uhrich, 2014, que pesquisaram o tema cocriação de valor em diversos campos do saber, identificando sua forte horizontalidade com vários outros campos do conhecimento, como pode ser confirmado por meio da Tabela 1 deste estudo.

Tabela 1 - Temas abordados sobre cocriação de valor

Revista Eletrônica de Estratégia \& Negócios, Florianópolis, v.9, n.1, jan./abr. 2016. 
Business \& Economics

Computer Science

Business, Management and Accounting: Marketing

8

Business \& Economics, Engineering

Business and Economy

Business, Management and Accounting

Business, Management and Accounting: Business and International Management

Business, Management and Accounting: Organizational Behavior and Human Resource Management

Business, Management and Accounting: Tourism, Leisure and Hospitality Management

Psychology; Family Studies

Social Science

Arts and Humanities

Business \& Economics, Comunication

Business \& Economics, operation researchs \& Management Science

Business \& Economics, Communication

Business\& Economics

Business, Management and Accounting: Management of Technology and Innovation

Business, Management and Accounting: Marketing

Business, Management and Accounting: Strategy and Management

Communication

Communication, Governament e Law

Cutural studies \& Communication

Engineering

Engineering, Operation researchs \& Management Science

Georgia Institute of Technology, College of Management

Health Care \& Science Services

Information Science

Information Science \& Library Science; Business \& Economics

Management and Accounting: Business and International Management

Multidisciplinary

Nursing

Psychology

Public Administration

Public, Environmental \& Occupational Health Fonte: Dados da pesquisa (2015).

De maneira geral e ao analisar mais profundamente os assuntos e/ou áreas do conhecimento que se vinculam com a cocriação de valor, verifica-se a horizontalidade, a interdisciplinaridade e, porque não dizer, a multidisciplinaridade que o citado tema tem com estas outras temáticas e/ou campos do saber na literatura acadêmica internacional. Tal aspecto versado nesta seção ajuda a entender a importância e a necessidade que o tema Revista Eletrônica de Estratégia \& Negócios, Florianópolis, v.9, n.1, jan./abr. 2016. 
cocriação de valor tem para outras áreas do conhecimento, impactando nas mesmas e fazendo fomentar, não somente o tema cocriação de valor, mas os outros temas que estão relacionados a ele.

Tal achado contribui para mostrar e enfatizar a essencialidade que o tema cocriação de valor exerce e tem para a difusão do conhecimento de outros assuntos e/ou áreas do conhecimento e vice-versa, no âmbito global literário, acarretando para a emergência da temática cocriação de valor no contexto mundial acadêmico. Com isso, contribui e impacta para seu crescimento e emergência, fazendo com que, em um futuro próximo, tal assunto seja e tenha uma envergadura robustecida e realçada, por meio de outros estudos e estudiosos sobre o tema, na literatura científica global e, consequentemente, nacional.

\section{CONSIDERAÇÕES FINAIS}

Este trabalho investigou as características da produção científica do tema Cocriação de Valor nas bases de dados Web of Science e Scopus no período de 2000 a 2014, por meio de técnicas de análise bibliométrica em 97 artigos identificados.

Foram priorizados os artigos que continham os termos Cocreation, Co-creation, Value Co-creation e Value Cocreation. Para tanto, os critérios foram as revistas que publicaram artigos sobre a temática que tinham fator de impacto mais elevado, os anos que houve maior quantidade de publicações, os artigos e autores mais citados, os que foram encontrados com maior número de co-autorias, autores mais profícuos, IES que mais publicaram e, por consequência, a evidência dos países que mais se destacam em número de publicações e, por fim, os temas e/ou áreas do conhecimento que foram identificadas e abordadas no que se refere ao tema principal, cocriação de valor.

Observou-se que os anos de 2002 e 2003 foram os que menos publicaram, e notouse a ascendência de artigos publicados na temática a partir do ano de 2008 . Os anos que tiveram mais artigos foram os de 2012 e 2014. Esta ascensão resulta do interesse de outras áreas do saber de atuação pela cocriação de valor que, até 2008 , era valorizada na área de Marketing e suas vertentes. Desses 97 artigos encontrados, os EUA tiveram 43 publicações e, em sua maioria, a University System of Georgia foi a que mais se evidenciou quanto a publicações de artigos sobre o assunto cocriação de valor, seguida pelas IES Netherlands na Revista Eletrônica de Estratégia \& Negócios, Florianópolis, v.9, n.1, jan./abr. 2016. 
Ressenlaer Polytechinic Institute e Karlstand University em England. Ficou eminente, durante a pesquisa, que os países mencionados acima e suas respectivas IES não se destacam somente pela produtividade científica do tema cocriação de valor, mas em outras áreas de pesquisa e atuação, sobretudo nos Negócios e Economia.

De maneira geral, este estudo conclui e contribui para a literatura acadêmica com um perfil macro de artigos internacionais que envolvem o tema cocriação de valor, desde seu inicio, ou seja, com as primeira pesquisas de Prahalad e Ramaswamy (2000), até os dias de hoje, envolvendo uma temporalidade de 15 anos. Os resultados e achados deste estudo contribuíram para a literatura científica global, pois, antes dele, nenhum outro similar fora realizado, proporcionando, com isso, sua legítima importância no contexto científico internacional. Desta forma, colaborando para elucidar e propagar dados e informações em todas as suas nuances, inerentes ao tema cocriação de valor, propiciando informações preponderantes e essenciais para esclarecer pontos e deixar mais transparente sua importância como tema emergente no panorama acadêmico internacional.

Com isso, colocará em ênfase sua devida essencialidade, pois, como visto neste estudo, a cocriação de valor também pode ser evidenciada e contemplada como assunto horizontal, interdisciplinar e multidisciplinar, ajudando não apenas em sua própria propagação nas veias acadêmicas internacionais, também a impactar e ajudar a evoluir outros assuntos e/ou áreas do conhecimento que se fazem inerentes a ela, como é o caso da gestão dos negócios na economia mundial (PRAHALAD; RAMASWAMY, 2004; VARGO; LUSCH, 2004).

Este estudo limitou-se em investigar e analisar a produção acadêmica dos artigos internacionais divulgados nas bases do Web of Science e Scopus de 2000 a 2014. Contudo, é valido e importante realçar que os achados deste estudo foram devidamente suficientes para responder à questão de pesquisa proposta. Diante do exposto, ressalta-se que a produção científica é importante para sociabilização entre os pesquisadores, além da disseminação do conhecimento, e vale ressaltar que, durante a pesquisa bibliométrica percebeu-se a carência de publicações em âmbito internacional pelo Brasil, pois foi localizado apenas um artigo brasileiro dentre os 97 encontrados.

Revista Eletrônica de Estratégia \& Negócios, Florianópolis, v.9, n.1, jan./abr. 2016. 
Diante do exposto sugere-se, para estudos futuros, a busca de melhor entendimento, de como os estudos sobre cocriação de valor, como está sendo difundido e socializado no Brasil por meio de uma pesquisa similar a esta, mas não apenas com estudos publicados em periódicos nacionais, mas com pesquisas divulgadas em congressos, seminários, e também em dissertações e teses. Deste modo, não contemplaria apenas as pesquisas acabadas, mas os estudos em fase de projetos de pesquisas e em fase de produtos em elaboração. Outra sugestão para futuros estudos é poder realizar uma análise de conteúdo dos 97 artigos para maior compreensão do comportamento da literatura internacional do tema de cocriação de valor.

\section{REFERÊNCIAS}

AAPAOJA, A.; HAAPASALO, H.; SÖDERSTRÖM, P. Early Stakeholder Involvement in the Project Definition Phase: Case Renovation. ISRN Industrial Engineering, v. 2013, p. 1-14, 2013.

ACEDO, F. J.; CASILLAS, J. C. Current paradigms in the international management field: an author co-citation analysis. International Business Review, v. 14, p. 619-639, 2005.

ALVARADO, R. U. A lei de Lotka na bibliometria brasileira. Revista Ciência da Informação, v. 31, n. 2, p. 14-20, 2002.

BALESTRIN, A.; VERSCHOORE, J. R.; REYES JUNIOR, E. O campo de estudo sobre redes de cooperação interorganizacional no Brasil. Revista de Administração Contemporânea, v. 14, n. 3, p. 458-477, 2010.

BARDIN, L. Análise de conteúdo. Lisboa: Edições 70, 2009.

BAR-ILAN, J. Which h-index?-A comparison of WoS, Scopus and Google Scholar. Scientometrics, v. 74, n. 2, p. 257-271, 2008.

BECKER, L. C. B.; DE BRITO NAGEL, M. A relação entre os elementos da cocriação (DART) e confiança no contexto de serviços. Revista de Administração IMED, v. 3, n. 1, p. 1-18, 2013.

BORNMANN, L. Mimicry in science? Scientometrics, v. 86, n. 1, p. 173-177, 2010.

BUFREM, L.; PRATES, Y. O saber científico registrado e as práticas de mensuração da informação. Revista Ciência da Informação, v. 34, n. 2, p. 9-25, 2005.

CAI, K-Y.; CARD, D. An analysis of research topics in software engineering-2006. Journal of Systems and Software, v. 81, n. 6, p. 1051-1058, 2008. 
COOPER, H. M.; LINDSAY, J. J. Research synthesis and meta-analysis. In L. Bickman \& D. J. Rog (Eds.), Handbook of applied social research methods (pp. 315-342). Thousand Oaks, CA: Sage Publications, 1998.

CRONIN, B. Bibliometrics and beyond: some thoughts on web-based citation analysis. Journal of Information Science, v. 27, n. 1, p. 1-7, 2001.

CRUZ, C.; RIBEIRO, U. Metodologia científica: teoria e prática. Rio de Janeiro: Axcel Books, 2003.

DAIM, T. U.; RUEDA, G.; MARTIN, H.; GERDSRI, P. Forecasting emerging technologies: Use of bibliometrics and patent analysis. Technological Forecasting and Social Change, v. 73, n. 8, p. 981-1012, 2006.

DEGNEGAARD, R., DEGNEGAARD, S., COUGHLAN, P. How to design for large-scale multistakeholder co-creation initiatives: reframing crime prevention challenges with the police in Denmark. Journal of Design, Business \& Society, v. 1, n. 1, p. 7-28, 2015.

EGGHE, L. Zipfian and lotkaian continuous concentration theory. Journal of the American Society for Information Science and Technology, v. 56, n. 9, p. 935-945, 2005.

EL-MAAMIRY, A. A.; ABID GHAURI, M. Measuring Information Quality: Concerns on the Use of Bibliometric Studies. International Journal of Information Dissemination \& Technology, v. 3, n. 4, 274-278, 2013.

FALAGAS, M. E.; PITSOUNI, E. I.; MALIETZIS, G. A.; PAPPAS, G. Comparison of PubMed, Scopus, web of science, and Google scholar: strengths and weaknesses. The FASEB Journal, v. 22, n. 2, p. 338-342, 2008.

FERREIRA, M. P.; PINTO, C.; SERRA, F.; FILIPE, L. John Dunning's influence in international business/strategy research: a bibliometric study in the strategic management journal. Journal of Strategic Management Education, v. 7, n. 2, p. 1-24, 2011.

GALVAGNO, M.; DALLI, D. Theory of value co-creation: a systematic literature review. Managing Service Quality, v. 24, n. 6, p. 643-683, 2014.

GLÄNZEL, W.; DEBACKERE, K.; THUS, B.; SCHUBERT, A. A concise review on the role of author self-citations in information science, bibliometrics and science policy. Scientometrics, v. 67, n. 2, p. 263-277, 2006.

GRÖNROOS, C. Creating a relationship dialogue: communication, interaction and value. The Marketing Review, v. 1, n. 1, p. 5-14, 2000.

GRÖNROOS, C.; RAVALD, A. Service as business logic: implications for value creation and marketing. Journal of Service Management, v. 22, n. 1, p. 5-22, 2011.

GUZ, A. N.; RUSHCHITSKY, J. J. Scopus: A system for the evaluation of scientific journals. International Applied Mechanics, v. 45, n. 4, p. 351-362, 2009. 
HAYASHI, M. C. P. I.; HAYASHI, C. R. M.; SILVA, M. R.; LIMA, M. Y. Um estudo bibliométrico da produção científica sobre a educação jesuítica no Brasil colonial. Biblios: Revista Electrónica de Bibliotecología, Archivología y Museología, v. 8, n. 27, p. 1-18, 2007.

HEDLUND, D. P. Creating value through membership and participation in sport fan consumption communities. European Sport Management Quarterly, v. 14, n. 1, p. 50-71, 2014.

HID, D. S.; NASCIMENTO, C.; OLIVEIRA, D. A. Análise das publicações internacionais relacionadas ao desenvolvimento sustentável na área de administração: uma análise bibliométrica da produção científica. Administração: Ensino e Pesquisa, v. 13, n. 4, p. 653671, 2012.

HOFFMAN, D. L.; HOLBROOK, M. B. The intellectual structure of consumer research: a bibliometric study of author cocitations in the first 15 years of the journal of consumer research. Journal of Consumer Research, v. 19, p. 505-517, 1993.

HONG YEOH, K.; KAUR, K. Subject support in collection development: Using the bibliometric tool. Collection Building, v. 27, n. 4, p. 157-166, 2008.

HOYER, W. D.; CHANDY, R.; DOROTIC, M.; KRAFFT, M.; SINGH, S. S. Consumer cocreation in new product development. Journal of Service Research, v. 13, n. 3, p. 283-296, 2010.

MCCOLL-KENNEDY, J. R.; VARGO, S. L.; DAGGER, T. S.; SWEENEY, J. C.; VAN KASTEREN, Y. Health care customer value cocreation practice styles. Journal of Service Research, v.15, n. 4, p.370-389, 2012.

MICHELS, C.; SCHMOCH, U. Impact of bibliometric studies on the publication behaviour of authors. Scientometrics, v. 98, n. 1, p. 369-385, 2014.

MORAES, M. B.; COSTA, B. K. Co-criação de valor e perspectiva da lógica dominante: um estudo em uma empresa do setor aeronáutico. Revista Brasileira de Gestão e Desenvolvimento Regional, v. 9, n. 2, 2013.

MORETTI, S. L. A.; CAMPANÁRIO, M. de A. A produção intelectual brasileira em responsabilidade social empresarial - RSE sob a ótica da bibliometria. Revista de Administração Contemporânea, v. 13, Edição Especial, p. 68-86, 2009.

NAMBISAN, S.; NAMBISAN, P. How to profit from a better'virtual customer environment'. MIT Sloan Management Review, v. 49, n. 3, p. 53, 2008.

NASCIMENTO, S. do; BEUREN, I. M. Redes sociais na produção científica dos programas de pós-graduação de ciências contábeis do Brasil. Revista de Administração Contemporânea, v. 15, n. 1, p. 47-66, 2011.

NASCIMENTO, A. R. do; JUNQUEIRA, E.; MARTINS, G. A. de. Pesquisa Acadêmica em Contabilidade Gerencial no Brasil: Análise e Reflexões sobre Teorias, Metodologias e Paradigmas. Revista de Administração Contemporânea, v. 14, n. 6, p. 1113-1133, 2010. 
NEDERHOF, A. J. Bibliometric monitoring of research performance in the social sciences and the humanities: A review. Scientometrics, v. 66, n. 1, p. 81-100, 2006.

PAYNE, A. F.; STORBACKA, K.; FROW, P. Managing the co-creation of value. Journal of the Academy of Marketing Science, v. 36, n. 1, p. 83-96, 2008.

PINHEIRO, C. M. P.; BARTH, M.; SCHMIDT, S.; SCHREIBER, D. Mapeamento de conhecimento na plataforma Scopus: um estudo sobre a indústria criativa. Revista Digital de Biblioteconomia e Ciência da Informação, v. 13, n. 2, p. 329-342, 2015.

PRAHALAD, C. K.; RAMASWAMY, V. Co-creation experiences: the next practice in value creation. Journal of Interactive Marketing, v. 18, n. 3, p. 5-14, 2004.

PRAHALAD, C. K.; RAMASWAMY, V. Co-opting customer competence. Harvard Business Review, v. 78, n. 1, p. 79-90, 2000.

RAMASWAMY, V. Co-creating value through customers' experiences: the Nike case. Strategy \& Leadership, v. 36, n. 5, p. 9-14, 2008.

RAMASWAMY, V.; GOUILLART, F. Building the co-creative enterprise. Harvard Business Review, v. 88, n. 10, p. 100-109, 2010.

RANJAN, K. R.; READ, S. Value co-creation: concept and measurement. Journal of the Academy of Marketing Science, p. 1-26, 2014.

REW, D. Scopus: Another step towards seamless integration of the world's medical literature. European Journal of Surgical Oncology (EJSO), v. 36, n. 1, p. 2-3, 2010.

RIBEIRO, H. C. M. Características da produção veiculada na Revista de Educação e Pesquisa em Contabilidade no período de 2007 a 2012. Revista de Educação e Pesquisa em Contabilidade, v. 7, n. 4, p. 424-443, 2013.

RIBEIRO, H. C. M. Corporate governance versus corporate governance: an international review: uma análise comparativa da produção acadêmica do tema governança corporativa. Revista Contemporânea de Contabilidade, v. 11, n. 23, p. 95-116, 2014.

RIBEIRO, H. C. M.; COSTA, B. K.; FERREIRA, M. A. S. P. V. Produção acadêmica dos temas estratégia e governança corporativa. Revista de Administração FACES, v. 13, n. 3, p. 27-46, 2014.

RIBEIRO, H. C. M.; COSTA, B. K.; FERREIRA, M. P. Governança corporativa nos esportes: análise dos últimos 23 anos de produção acadêmica em periódicos internacionais. Revista de Administração e Contabilidade da Unisinos, v. 12, n. 2, p. 135-154, 2015.

RIBEIRO, H. C. M.; MURITIBA, S. N.; MURITIBA, P. M.; DOMINGUES, L. M. Entender para progredir: análise da pesquisa em governança corporativa no Brasil. Gestão

Contemporânea, v. 9, n. 12, p. 11-42, 2012.

Revista Eletrônica de Estratégia \& Negócios, Florianópolis, v.9, n.1, jan./abr. 2016. 
SERRA, F. R.; FERREIR, M. P.; ALMEIDA, M. I. R.; VANZ, S. A. S. A pesquisa em administração estratégica nos primeiros anos do século XXI: um estudo bibliométrico de citação e cocitação no Strategic Management Journal entre 2001 e 2007. Revista Eletrônica de Estratégia \& Negócios, v. 5, n. 2, p. p.257-274, set. 2012.

SMITH, D. R.; HAZELTON, M. Bibliometrics, citation indexing, and the journals of nursing. Nursing \& Health Sciences, v. 10, n. 4, p. 260-265, 2008.

SOUZA, F. J. V. de; SILVA, M. C. da; ARAÚJO, A. O.; SILVA, J. D. G. da. Revista de Contabilidade do Mestrado em Ciências Contábeis da UERJ: uma análise de oito anos de publicação (2003 a 2011). Revista de Administração, Contabilidade e Sustentabilidade, v. 2, n. 3, p. 69-85, 2012.

SPINAK, E. Diccionario enciclopédico de bibliometría, cienciometría e informetría. Montevideo: UNESCO, 2013.

SUBRAMANYAM, K. Bibliometric studies of research collaboration: A review. Journal of information Science, v. 6, n. 1, p. 33-38, 1983.

SZU-CHIA, S. L. Scientific linkage of science research and technology development: a case of genetic engineering research. Scientometrics, v. 82, n. 1, p. 109-120, 2010.

TSAl, H-H. Knowledge management vs. data mining: Research trend, forecast and citation approach. Expert Systems with Applications, v. 40, n. 8, p. 3160-3173, 2013.

UHRICH, S. Exploring customer-to-customer value co-creation platforms and practices in team sports. European Sport Management Quarterly, v. 14, n. 1, p. 25-49, 2014.

VANTI, N. A. P. Da bibliometria à webometria: uma exploração conceitual dos mecanismos utilizados para medir o registro da informação e a difusão do conhecimento. Revista Ciência da Informação, v. 31, n. 2, p. 152-162, 2002.

VARGO, S. L.; LUSCH, R. F. Evolving to a new dominant logic for marketing. Journal of Marketing, v. 68, n. 1, p. 1-17, 2004.

VIEIRA, E.; GOMES, J. A comparison of Scopus and Web of Science for a typical university. Scientometrics, v. 81, n. 2, p. 587-600, 2009.

WASSERMAN, S.; GALASKIEWICZ, J. Advances in social network analysis: Research in the social and behavioral sciences. Sage Publications, 1994.

WEINGART, P. Impact of bibliometrics upon the science system: Inadvertent consequences? Scientometrics, v. 62, n. 1, p. 117-131, 2005.

YUNIS, M.; KOONG, K. S.; LIU, L. C.; KWAN, R.; TSANG, P. ICT maturity as a driver to global competitiveness: a national level analysis. International Journal of Accounting \& Information Management, v. 20, n. 3, p. 255-281, 2012. 
ZAUBER, A. G.; WINAWER, S. J.; O'BRIEN, M. J.; LANSDORP-VOGELAAR, I.; VAN

BALLEGOOIJEN, M.; HANKEY, B. F.; WAYE, J. D. (2012). Colonoscopic polypectomy and longterm prevention of colorectal-cancer deaths. New England Journal of Medicine, v. 366, n. 8 , p. 687-696, 2012.

ZHANG, X.; CHEN, R. Examining the mechanism of the value co-creation with customers. International Journal of Production Economics, v. 116, n. 2, p. 242-250, 2008. 